\title{
The World War II Origins of Mathematics Awareness
}

Michael J. Barany

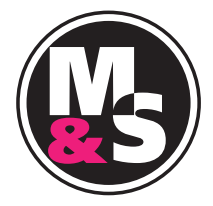

Since ancient times, advocates for mathematics have argued that their subject is foundational for many areas of human endeavor, though the areas and arguments have changed over the years. Much newer, however, is the idea that mathematicians should systematically try to promote the usefulness or importance of mathematics to the public. This effort, which I shall generically call "mathematics awareness," was largely an American inven-

\section{To understand} the origins of mathematics awareness, one must follow the money. tion. One outward manifestation was the 1986 inauguration, by President Ronald Reagan, of the first Mathematics Awareness Week. Every year since then, mathematicians and mathematics educators in the United States have dedicated a weekor, beginning in 1999, the month of April-to raising public awareness of "the importance of this basic branch of science to our daily lives," as Reagan put it.

While today's mathematics awareness is focused on schools and on peaceful applications of mathematics, a direct line connects it to its origins in a very different kind of activity: mathematicians promoting their expertise to leaders of the American war effort during World War II. Recent mathematics awareness has focused on encouraging

Michael J. Barany is a postdoctoral fellow in the Dartmouth College Society of Fellows. His e-mail address is michae1@mbarany.com, and his website is mbarany. com.

For permission to reprint this article, please contact:

reprint-permission@ams.org.

DOI: http://dx.doi.org/10.1090/noti1506

\section{A War of Mathematics}

World War II was not the first war that mathematicians attempted to characterize as "a war of mathematics," but it was the first one where the characterization appeared to stick. In addition to lobbying elite policymakers, mathematicians wrote articles for the popular press and offered radio broadcasts that attempted to explain why mathematics mattered in terms the masses could understand. For example, Bennington P. Gill, who served as AMS treasurer from 1938 to 1948, gave an interview in 1942 with WNYC for their series on The Role of Science in War, see Www. wnyc. org/story/ bennington-p-gi11/.

more people to take up the discipline. However, wartime and early postwar mathematics awareness centered on securing resources for those already in the profession. To understand the origins of mathematics awareness, one must follow the money.

\section{A Discipline in Need}

For most of the discipline's history, mathematicians have supported their research either through independent wealth or through patronage from the wealthy. Universities and a select few other academic institutions-all, themselves, historically channels for wealthy patronage-eventually became the dominant sites and funders of mathematical scholarship. So long as publication and travel were relatively small parts of such scholarship, this arrangement suited mathematicians' needs well enough. But by the early twentieth century mathematicians were publishing and traveling much more than before and across greater distances. They needed new organizations and new sponsors to support their work.

Such were the rationales for mathematicians' first professional societies, many of which date to the latter part of the nineteenth century and the start of the twentieth. 


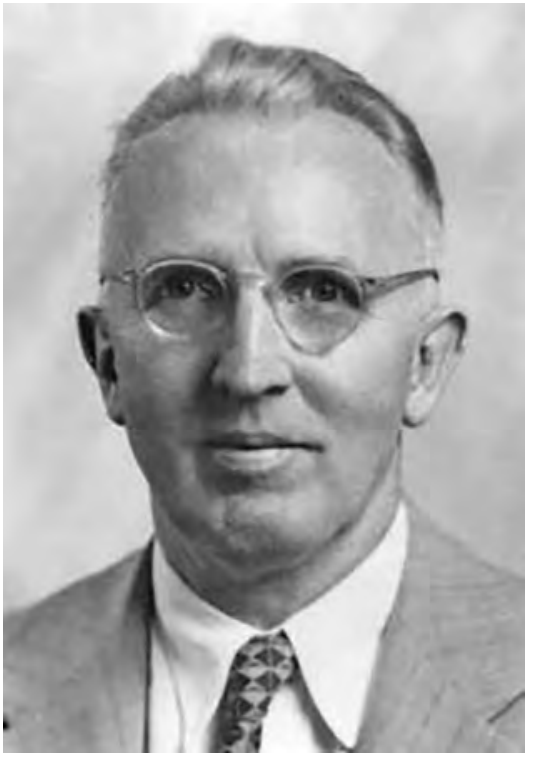

IAS mathematician Marston Morse, who served as AMS president during 1941-1942, approached the Rockefeller Foundation with the argument that his discipline was "unique... as having no natural sources of support."

porate sponsorship for their work, for instance from the American Telephone \& Telegraph Company, and considerably greater success courting major philanthropies such as the Rockefeller Foundation and Carnegie Corporation of New York. Yet these relationships tended to be piecemeal and tenuous. American mathematicians had successfully bid to host the 1924 International Congress of Mathematicians but ended up ceding the congress to Toronto after finding themselves unable to secure the needed financial backing. (John Charles Fields, on the other hand, managed to find enough money for the Toronto meeting that it concluded with a modest surplus, which provided the seed money for what became the Fields Medals.)

The Americans tried again to host an International Congress in 1940. When preliminary fundraising efforts again fell short, Institute for Advanced Study mathematician Marston Morse approached the Rockefeller Foundation with the argument that his discipline was "unique... as having no natural sources of support." Indeed, when it came to major donors, Rockefeller and Carnegie were the only relatively sure bets, and no grant was assured. To grow, American mathematics would need new constituencies and new sources of funding.

\section{Preparing for War}

The AMS suspended plans for the envisioned 1940 International Congress of Mathematicians following the German invasion of Poland in 1939. As war threatened to engulf Europe and beyond, American mathematicians thought back to their experiences of the Great War. Some concluded that a lack of coordination among American mathematicians had restricted their contributions to the previous war effort. Without such coordination, military leaders would have a hard time learning where mathematicians were needed and where the needed mathematicians could be found.

A new joint AMS-MAA War Preparedness Committee aimed to provide this coordination by synthesizing the lessons from the last war and positioning mathematicians for a new conflict that seemed sure to draw American involvement sooner or later. Marston Morse was appointed chair, and a subcommittee chaired by Dunham Jackson focused on mathematical research. The subcommittee included Marshall Stone, whose two-year presidency of the AMS would fall in the middle of the United States' official engagement in World War II. From start to finish, Stone advocated formal mathematical coordination with particular force and frequency. In a summer 1940 missive on "the organizational aspects of the research problems of national defense," Stone articulated three purposes for the subcommittee. First and most urgent was to find an efficient means to join together current "technical problems and competent mathematicians" who could solve them. Second, the US would need to make much greater use of mathematical techniques than it currently did. The third, long-range, goal was to make war service pay off for the US mathematical profession even after the war's end.

"If mathematics is to be brought to bear upon our defense problems in full measure," Stone then asserted, "we shall have to organize and conduct propaganda to this end." He anticipated an uphill struggle. The subcommittee would have to confront "not only the appalling limitations of our military officers, but also the general American attitude of antagonism to theory in general and to mathematical refinements in particular and the abysmal ignorance of the majority of intelligent Americans concerning the uses of mathematics."

\section{Enter Mina Rees}

The US military officially entered the war as 1941 drew to a close. The next year the AMS and MAA responded by dissolving the War Preparedness Committee and appointing a new War Policy Committee, with Marshall Stone (soon to be AMS president) as chair and Marston Morse (who was just finishing his own term as AMS president) in a supporting role. Soon, leaders from academia, philanthropy, and the military drew on approaches from their respective fields to develop for the US government a system for identifying problems and contracting them out to academic research groups. This formed the basis for a massive system of contracts that would support advanced mathematical research and training after the war, as well as the postwar system of government grants familiar to many mathema- 
ticians today. But mathematics awareness remained the exclusive province of a narrow elite.

Richard Courant, one of the academic leaders who helped to craft that system, used his wartime government connections both during and after the war to build his institute at New York University into one of the world's leading centers of mathematics. Perhaps even more important for postwar mathematics in and beyond the United States, however, was Courant's close associate Mina Rees. Although she had earned a PhD under Leonard Dickson from the University of Chicago, Rees's prospects within the mathematics profession were limited by widespread institutional sexism. At Courant's urging, Rees was appointed

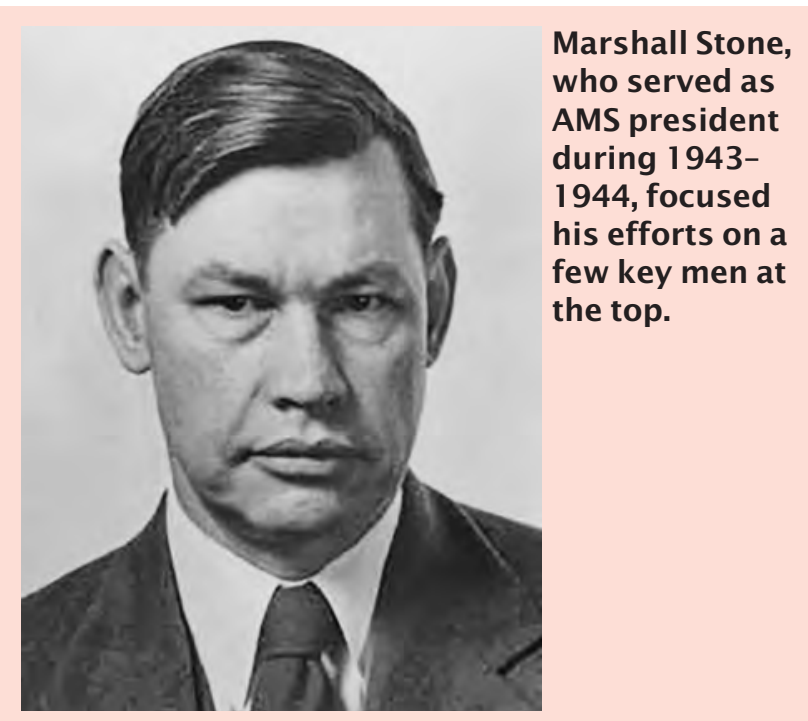

A Few Key Men at the Top

Marshall Stone's dim view of the public appreciation for mathematics led him to focus on a few "key men at the top" rather than aim to convince the masses or even the much smaller mass of officers and policymakers. Among those key men were Harvard president James Bryant Conant, chair of the National Defense Research Committee, and Frank Jewett, chairman of the Board of Directors of Bell Laboratories and president of the National Academy of Sciences. Referring to the commonplace characterization of the Great War as the chemist's war, Conant famously quipped on the front page of Chemical \& Engineering News in November 1941,"This is a physicist's war rather than a chemist's." According to AMS secretary Roland Richardson, when Conant shared the view with Jewett the latter shot back that "It may be a war of physics, but the physicists say it is a war of mathematics." At least one key man got the message.

Further Reading: Michael J. Barany, "Remunerative combinatorics: Mathematicians and their sponsors in the mid-twentieth century," in Mathematical Cultures: The London Meetings 2012-2014, edited by Brendan Larvor (Basel: Birkhäuser, 2016), pp. 329-346; preprint online at mbarany.com/publications.htm7. as technical aide to the main government clearinghouse for coordinating mathematicians' war service. There, she facilitated the broad array of contracts by gathering information, assessing outcomes, and making needed connections.

Stone, in 1944, expressed his frustration that the government "would display considerable reluctance to call on the leaders of our profession." In his view, mathematicians could and should have done much more to dedicate themselves wholly to the war effort. He himself set out immediately after the conclusion of his term as AMS president on a mission classified top secret to advise and assess Allied signal intelligence in India, Burma, and China in the first part of 1945.

Mathematicians in the US concluded the war with a range of views of their relative success or failure. While they did not lay claim to a breakthrough on the scale of the Manhattan Project as physicists would, mathematicians contributed to a great many of the United States' decisive wartime innovations in weaponry, aeronautics, provisioning, communications and intelligence, and other areas.

\section{Coordination for a Growing Discipline}

In 1946 Rees took over the mathematics arm of the Office of Naval Research (ONR), helping the navy to become a leading funder of research and publication in both pure and applied mathematics. One of her earliest efforts was to forge a partnership with the AMS's Mathematical Reviews to translate new Russian mathematical works into English. This and related undertakings reinforced the United States as an international clearinghouse for postwar mathematics, allowing American institutions to assume a lasting dominance in the discipline.

The ONR led the way for a wide range of government-funded research programs associated with other branches of the military and various civilian offices. These eventually included the National Science Foundation, founded in 1950 after years of debate informed by wartime and early postwar military-sponsored science. ONR and other contracts funded faculty, students, seminars, and publications on a wide scale in the first postwar decades. They supported visiting researchers from abroad and allowed US mathematicians to disseminate their work rapidly and efficiently. These new funding sources allowed the mathematics profession to grow quickly-so quickly, in fact, that US mathematicians could turn from worrying about finding enough sources of support to worrying about finding enough people to make good use of that support.

Over the years, as new mathematical organizations sprang up and the mathematical profession collectively faced new funding and policy issues, the AMS and MAA continued to adapt and reconfigure a series of joint undertakings aimed at the kind of mathematics awareness pursued in the 1940s. ${ }^{1}$ Early postwar joint committees

\footnotetext{
${ }^{1}$ For a blow-by-blow account of the various joint committees, see Everett Pitcher, A History of the Second Fifty Years: American Mathematical Society, 1939-1988 (Providence: American Mathematical Society, 1988), pp. 273-285.
} 


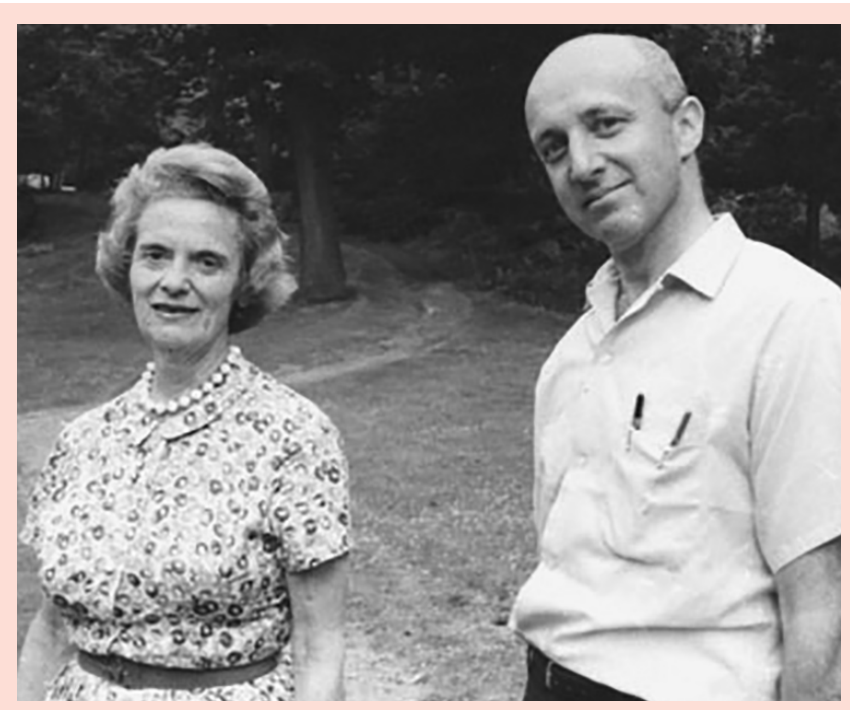

Mina Rees, pictured here around 1966 with Leon Henkin, had an enormous impact in her position as head of the mathematics arm of the Office of Naval Research.

\section{Mina Rees}

In recognition of Rees's contributions to the mathematics profession, the AMS Council adopted a resolution in 1953 asserting:

Under her guidance, basic research in general, and especially in mathematics, received the most intelligent and wholehearted support. No greater wisdom and foresight could have been displayed and the whole postwar development of mathematical research in the United States owes an immeasurable debt to the pioneering work of the Office of Naval Research and to the alert, vigorous and farsighted policy conducted by Miss Rees. (Quoted from the Bulletin of the AMS, March 1954.)

Rees continued after 1953 to serve as an administrator and advisor for a wide range of important boards and institutions, fostering the development of pure and applied mathematics in and beyond the United States.

Further reading: Judy Green, Jeanne LaDuke, Saunders MacLane, and Uta C. Merzbach, "Mina Spiegel Rees (1902-1997)," Notices of the American Mathematical Society 45, (1998) no. 7, 866-873; Amy Shell-Gellasch, In Service to Mathematics: The Life and Work of Mina Rees (Boston: Docent Press, 2011).

laid the groundwork for the International Mathematical Union and advocated for the new NSF and a mathematics division in the National Research Council. The 1970sera Joint Projects Committee in Mathematics eventually grew into the Joint Policy Board for Mathematics, which currently spearheads the annual Mathematics Awareness Month (in 2017 the name became Mathematics and Statistics Awareness Month).

\section{A New Wave}

If more people saw how important math was to their lives, the thinking since the 1980s has been, more people would participate in shaping that mathematics in the future. In practice, it has not always worked out that way. National and even international campaigns for mathematics education have put the power of mathematics on public display, but for many there remain significant barriers to success in the mathematical profession.

The first wave of mathematics awareness took place at a time when American mathematicians were relatively isolated from many areas of policy and the economy and correspondingly lacked obvious places to turn for resources. The second wave responded to a different problem: the need for a public posture that would assure a supply of mathematicians in the future. The Mathematics Awareness Weeks, and later Months, addressed that need by displaying the relevance of mathematics to modern life and to society at large.

We are now starting to see a third wave of mathematics awareness, focused less on what mathematics can do for war-making policy elites or for everyday citizens and more on the mathematicians themselves who create and apply that mathematics and train future generations in their field. Efforts to highlight women and minority pioneers in the discipline and to support underrepresented groups may yet make headway where other approaches have fallen short. The history of mathematics awareness shows that by banding together and working systematically, mathematics organizations can make real changes in how important constituencies view and engage the discipline. The history also shows that mathematics awareness can take many forms, each reflecting the priorities and blind spots of its time.

\section{Photo Credits}

Photo of Mina Rees is from the Marion Walter Photograph Collection, 1952-1980s, undated, Archives of American Mathematics, e_math_01146, Dolph Briscoe Center for American History, University of Texas at Austin.

Michael J. Barany, photo by Yana Stainova. 


\section{COMMUNICATION}

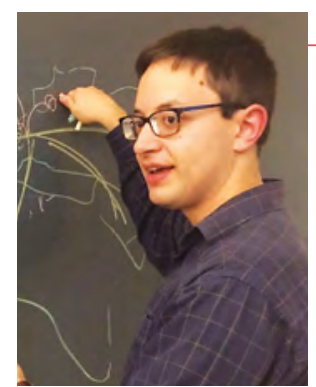

Michael J. Barany

\section{ABOUT THE AUTHOR}

Michael J. Barany is a historian of modern mathematics, currently at the Dartmouth College Society of Fellows. He recently completed his $\mathrm{PhD}$ at Princeton University on the topic of the globalization of the mathematics profession in the mid-twentieth century, with a focus on Laurent Schwartz's theory of distributions. His work on topics ranging from blackboards to "primitive" counting to the Fields Medal has appeared in the Notices of the AMS, New Scientist, The New York Times, and other publications not beginning with $\mathrm{N}$ (including twice in the Best Writing on Mathematics anthology).

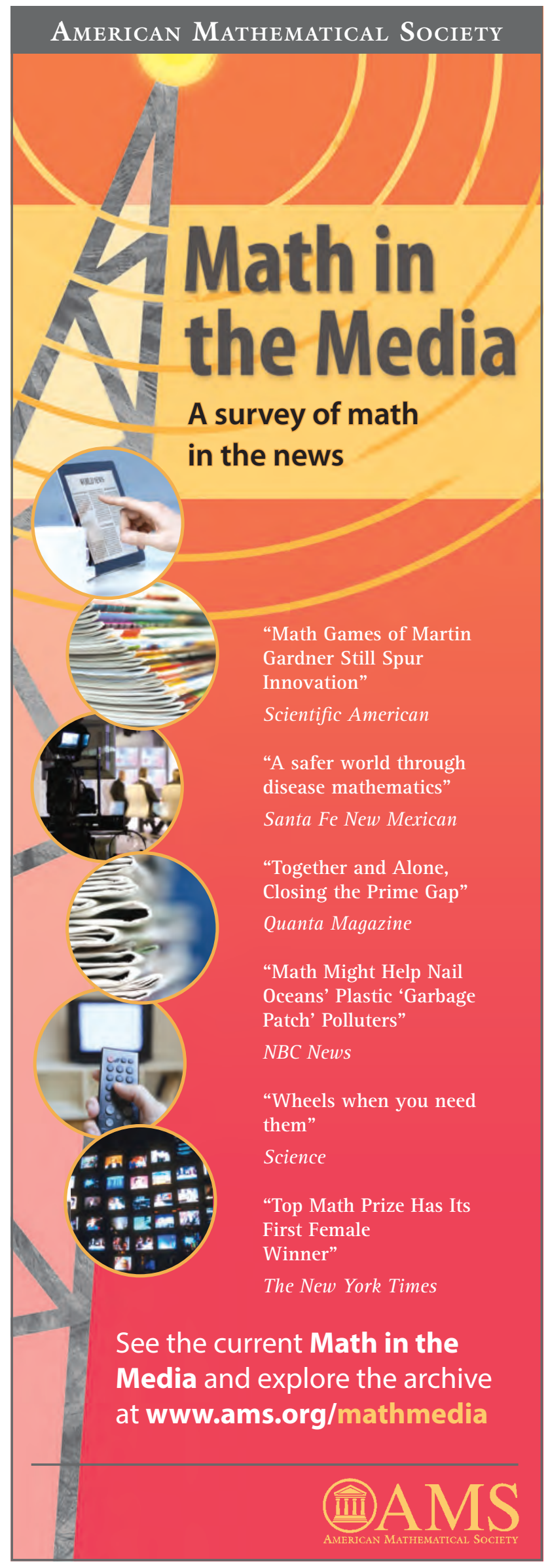

